\title{
Organic Versus Inorganic Management on the Yield and Soil Fertility of Irrigated Lowland Rice
}

\author{
Michelle C. Quimbo, Cezar P. Mamaril and Kathy Loren S. \\ Tafere
}

Philippine Rice Research Institute, Los Baños, College 4031 Laguna, Philippines

\begin{abstract}
Organic farming is being promoted by advocates to sustain and improve soil fertility compared to conventional farming that uses inorganic fertilizers and pesticides. The study was conducted to determine the effect of pesticide and fertilizer management practices on grain and straw yields, yield components, and soil fertility of irrigated lowland rice. The experiment was conducted for three consecutive seasons (2009-2010) at Los Baños, Laguna, Philippines. It was laid out in a Split Plot design consisting of two main plots: with pesticides (M1) and without pesticides (M2), and four subplots: control (T1), organic fertilizer only (T2), inorganic fertilizer only (T3), and one-half $(1 / 2)$ rate of inorganic plus $1 / 2$ rate of organic fertilizers (T4), with four replications. Generally, pesticide application did not affect the yield and yield components. Plots applied with inorganic and one-half rate of combined organic and inorganic fertilizers had significantly higher grain yields than the control and organic only fertilizer treatments. Application of limiting nutrients through inorganic fertilizers helps to correct most of soil deficiencies such as phosphorus and sulfur compared to the use of organic fertilizer alone. Combining organic materials such as compost and rice straw with inorganic fertilizers at one-half rates is an effective strategy to attain yields comparable to pure inorganic application to sustain soil fertility.
\end{abstract}

Keywords: conventional fertilization, organic fertilizers, inorganic fertilizers, pesticide application, soil fertility

Correspondence : M.C. Quimbo. Address: Philippine Rice Research Institute, Los Baños, College 4031 Laguna, Philippines Tel. No: 049-501-1917. E-mail: miccute_21@yahoo.com.ph / mbcastillo@philrice.gov.ph

DOI: $10.32945 /$ atr 3613.2014 


\section{INTRODUCTION}

The use of organic materials such as compost, manures, crop residues, commercial organic fertilizers, etc. is being promoted in developing and developed countries in recent years. This arises due to the increasing cost of inorganic fertilizers which is one of the most significant inputs in crop production. There is also an increasing concern to sustain and improve soil fertility and productivity through the use of organic amendments. Javier et al. (2002) showed that chicken manure was as good as inorganic fertilizer in terms of nutrient supplement and grain yield. The study conducted by Tilo and San Valentin (1984) showed no significant differences in yield between commercial organic fertilizer with $5 \% \mathrm{~N}$ (1.8 t/ha), dried azolla with $3.68 \% \mathrm{~N}$ ( $2.45 \mathrm{t} / \mathrm{ha})$, cow manure with $2 \% \mathrm{~N}$ ( $4.5 \mathrm{t} / \mathrm{ha}$, fresh weight), and urea with $46 \%$ applied at $90 \mathrm{~kg} \mathrm{~N} /$ ha suggesting that organic materials can be used to replace urea as fertilizer input. The long-term field experiment of Lales (2008) presented that grain yield of inorganic fertilizer alone at recommended level was consistently and significantly higher than commercial organic fertilizer alone at manufacturer's recommended level by $48 \%$ during the dry season and $11 \%$ during the wet season. However, the study showed that based on marginal benefitmarginal cost ratio, the most economically viable inorganic-organic fertilizer combination during the wet season was 50:50. This shows that the positive effect of organic fertilizer can be observed when it is combined with inorganic fertilizer.

Organic materials, however, are slow-releasing and low-nutrient containing materials which may not suffice to produce high yields expected from a particular crop such as lowland rice, and thus, will not be able to meet the food demand of a growing population.

Conventional farming where inorganic fertilizers and pesticides are continually used is said to be eroding the inherent productivity of soils. While it is true that injudicious use of chemical fertilizers, such as applying heavy amounts of macronutrients $\mathrm{N}, \mathrm{P}$ and $\mathrm{K}$ may cause nutrient imbalance in soils, the need to apply readily available nutrient source to a crop cannot be ignored. Cosico (2010) cited the remark of Dr. Emil Truog from the University of Wisconsin, a leading soil scientist who devoted 50 years of research on soils, saying that "No evidence exists that the judicious use of mineral fertilizers is injurious to soils or tends to produce crops which are unsatisfactory as feed for animals or food for man. In fact, evidence without end exists showing clearly the use of mineral fertilizers on depleted soils 
promotes the growth of crops which have superior nutritive values."

Contrary to the claim of some advocates, the overuse of pesticides is far more dangerous than chemical fertilizers. Most farmers make two to three applications of insecticides and one application of herbicides (Pingali, 1995). The indiscriminate use of pesticides including herbicides poses hazards to the soil, environment, and humans. According to Nwilene et al. (2011), pesticides that are applied to crops can volatilize and may be blown by winds into nearby areas, potentially posing a threat to wildlife. More importantly, the remains of these pesticides flow back to the streams and river. Some people at the other end will fetch it for drinking and for other domestic activities thus resulting to one ailment or the other depending on the concentration. Aktar et al. (2009) noted that pesticides are retained by soils at different degrees, depending on the interactions between soil and pesticide properties. The heavy treatment of soil with pesticides can cause a decline in the populations of beneficial soil microorganisms. Pesticide contamination poses significant risks to the environment and non-target organisms ranging from insects, plants, fish, and birds.

Due to the contrasting claims regarding the use of organic and inorganic fertilizers, and pesticide application, this study was undertaken to compare the effects of pesticide, inorganic and organic fertilizer applications on the yield of irrigated rice.

The objectives of the study are to determine: (1) the effect of pesticide application on grain and straw yields, and (2) the effect of organic and inorganic fertilizers to grain and straw yields, yield components, and soil fertility.

\section{MATERIALS AND METHODS}

\section{Experimental Design}

The study was conducted for three consecutive seasons, dry (April-July 2009), wet (August-December 2009), and dry (February-May 2010) at C8Area 3, Los Baños, Laguna, Philippines. The planting dates were quite offseason since the implementation was based on the availability of funds. Normally, dry season crop is planted in December/January while wet season is in June/July. The experiment was laid out in a Split Plot design consisting of two main plots: M1, with pesticides and M2, without pesticides, and four subplots: T1, control (no fertilizer applied), T2, organic only (compost at the rate of $3 \mathrm{t} \mathrm{ha}^{-1}$ ), T3, inorganic only (rate based on 
Minus One Element Technique recommendation), and T4, one-half ( $1 / 2)$ recommended rate of inorganic and $1 / 2$ recommended rate of organic. The treatments were replicated four times.

The varieties used were NSIC Rc146, NSIC Rc160, and Burdagol (traditional variety) for the three consecutive seasons, respectively. The soil of the location is classified as a Lipa clay with a pH of $6.3,0.14 \%$ total $\mathrm{N}$, $45 \mathrm{ppm}$ available $\mathrm{P}, 0.98 \mathrm{cmol}(+) \mathrm{kg}^{-1}$ soil exchangeable $\mathrm{K}, 46 \mathrm{ppm}$ sulfate-S, $9 \mathrm{ppm} \mathrm{Zn}$, and $24 \mathrm{ppm} \mathrm{Cu}$. The compost used had an average nutrient content of $0.33 \% \mathrm{~N}, 0.15 \% \mathrm{P}, 0.37 \% \mathrm{~K}$, and $0.36 \mathrm{ppm} \mathrm{S}$. The rate of nutrients applied for each season in each of the fertilizer treatments is shown in Table 1.

Table 1. Nutrient recommendation in each of the fertilizer treatments for every cropping season

\begin{tabular}{|c|c|c|c|}
\hline \multirow{3}{*}{ TREATMENT } & \multicolumn{3}{|c|}{ NUTRIENT RECOMMENDATION, kg ha-1 (N-P-K-S) } \\
\hline & 2009 DS & 2009 WS & $2010 \mathrm{DS}$ \\
\hline & NSIC Rc146 & NSIC Rc160 & Burdagol \\
\hline $\mathrm{T} 1$ & 0 & 0 & 0 \\
\hline $\mathrm{T} 2$ & $* 13-2-17-16$ & $* 10-7-7-6$ & $* 7-5-10-10$ \\
\hline T3 & ${ }^{\wedge} 120-0-0-24$ & ^120-0-30-24 & $\wedge 125-0-0-24$ \\
\hline $\mathrm{T} 4$ & $67-1-9-20$ & $65-4-19-15$ & $67-3-5-17$ \\
\hline
\end{tabular}

* Compost rate at 3 tha $^{-1}$

^Rate based on Minus-One Element Technique recommendation

Pesticides were applied due to pest problems such as caseworm, stemborer, and leaffolder during the early stage and rice bug during the reproductive stage of the crop. It was only applied to plots with pesticide treatments. On main plots applied with pesticides, the NSIC Rc146 crop was treated with Furadan insecticide $\left(3 \mathrm{~g} \mathrm{~kg}^{-1}\right.$ Carbofuran, $16.7-33.3 \mathrm{~kg}$ ha $\left.{ }^{1}\right) 28$ days after transplanting (DAT) and with Brodan 3.51 EC insecticide (210 $\mathrm{g} \mathrm{L}^{-1}$ Chlorpyrifos + $105 \mathrm{~g} \mathrm{~L}^{-1}$ BPMC [Fenobucarb], 2.5-3.5 tablespoons $\left(45 \pm 7.5 \mathrm{~mL} / 16 \mathrm{~L}^{-1}, 120 \mathrm{~mL} \mathrm{ha}^{-1}\right)$ insecticide 69 DAT. The NSIC Rc160 crop was applied with Bayluscide EC 250 molluscicide $\left(250 \mathrm{~g} \mathrm{~L}^{-1}\right.$ Niclosamide + $200 \mathrm{~g} \mathrm{~L}^{-1}$ methyl isobutylketone $+100 \mathrm{~g} \mathrm{~L}^{-1}$ isobutanol, $1 \mathrm{~L} \mathrm{ha}^{-1}$ ) $1 \mathrm{DAT}$, and Brodan 3.51 EC insecticide at 39 and 83 DAT. Burdagol was applied with Rilof H 500 EC herbicide (330 g L ${ }^{-1}$ Piperophos, and $170 \mathrm{~g} \mathrm{~L}^{-1} 2,4$-D Isobutyl Ester (AE), $\left.1.5 \mathrm{~L} \mathrm{ha}^{-1}\right) 6$ DAT, Nominee SC 100 herbicide $\left(105.5 \mathrm{~g} \mathrm{~L}^{-1}\right.$ Bispyribac sodium, 250-300 $\mathrm{ml} \mathrm{ha}^{-1}$ ) together with Agrisol A $150 \mathrm{~K}$ surfactant $\left(285 \mathrm{ml} \mathrm{L}^{-1}\right.$ Polyethylene sorbitan fatty acid $+475 \mathrm{~mL} \mathrm{~L}^{-1}$ Polyoxyethylene dodecyl ether, 250-300 $\mathrm{ml} \mathrm{ha}^{-1}$ ) 19 DAT and, Cymbush 5 EC insecticide ( $50 \mathrm{~g} \mathrm{~L}^{-1}$ Cypermethrin) at 42 and 62 days after transplanting. 
Quimbo et al.

\section{Data and Observations Gathered}

Grain and straw yields. Yields were obtained from a harvest area of $3 \mathrm{~m}$ $\mathrm{x} 4 \mathrm{~m}\left(12 \mathrm{~m}^{2}\right)$ per plot. The crop was cut at ground level, threshed, and weighed. One hundred grams of grain sample was oven-dried at $60^{\circ} \mathrm{C}$ for 72 hours to determine moisture content. Likewise, $500 \mathrm{~g}$ straw sample per plot was weighed fresh, then oven-dried at $70^{\circ} \mathrm{C}$ for at least 72 hours. Grain yield was expressed in tons per hectare $\left(\mathrm{t} \mathrm{ha}^{-1}\right)$ at $14 \%$ moisture content while straw yield was expressed in oven dry weight.

Yield components. Samples consisting of 12 hills were randomly selected from the border rows to measure plant height, number of tillers, and number of panicles. From the 12 hills selected per plot, 2 panicles per hill were randomly selected having a total of 24 panicle samples representing each plot. These samples were used to determine the performance of different treatments in terms of number of spikelets per panicle, and number of filled and unfilled grains per panicle.

\section{Determination of Soil Fertility}

The soil nutrient status every season of the different fertilizer treatments was determined through monitoring of deficient nutrients using the Minus-One Element Technique (MOET). It is a biological technique which operates in such a way that the plant extract elements from the soil and the amount absorbed from the soil are reflected on its relative growth (Descalsota et al., 2002). Therefore, the test can show farmers the limiting or deficient nutrient(s) in the soil. The basic principle of MOET is based on the Leibig's (1828) "law of the minimum" which states that the level of plant production or yield can be no greater than that allowed by the most limiting of the essential plant growth factors.

Initial soil sample was collected and analyzed to determine the nutrient deficiencies before the start of the experiment. The nutrient recommendation for the inorganic treatment (T3) was based on the result of the MOET test. Before the establishment of the $2^{\text {nd }}$ cropping, soil sample was again subjected to MOET test. The same test was conducted again before the establishment of the $3^{\text {rd }}$ crop.

\section{Statistical Analysis}

All the data were analyzed using SAS 9 software to determine the 
differences between treatment means at 5\% level of significance by Least Significant Difference (LSD).

\section{RESULTS AND DISCUSSION}

\section{Agronomic Analysis}

NSIC Rc146 (2009 DS). In general, plots that were not applied with pesticides produced significantly higher grain yield at $2.96 \mathrm{t} \mathrm{ha}^{-1}$ compared with $2.77 \mathrm{t} \mathrm{ha}^{-1}$ produced from plots that were treated with pesticides (Table 2). In terms of fertilizer management, highest yield was obtained from the control plot (T1) with $3.30 \mathrm{t} \mathrm{ha}^{-1}$ which was comparable to the organic treatment (T2) with $3.04 \mathrm{t} \mathrm{ha}^{-1}$. One-half rate of organic plus onehalf inorganic (T4) yielded $2.77 \mathrm{t} \mathrm{ha}^{-1}$ which was also comparable with the yields of T2 and T3. Inorganic only (T3) yielded the lowest at $2.40 \mathrm{t} \mathrm{ha}^{-1}$. Straw yield showed no significant differences between the main plots and the subplots treatments. It ranged from 7.4 to 8.2 tha $^{-1}$ (Table 2).

For plant height, taller plants were observed when the plots were applied with pesticide $(112.0 \mathrm{~cm})$ compared to those that were not applied with pesticides $(105.4 \mathrm{~cm})$ regardless of fertilizer management. This observation was in contrast to the results obtained from grain yield. Plant heights of T3 and T4 having 113.9 and $109.6 \mathrm{~cm}$, respectively, were taller compared to 105.5 and $105.8 \mathrm{~cm}$ for T1 and T2, respectively (Table 3). In general, no significant differences were observed in yield components with different pesticide management but obtained significant differences in fertilizer management. Treatment 3 had the most number of tillers with 22 compared to T1, T2 and T4 with only 19 and 20, respectively. The same trend was observed for panicle count. T1 and T2 both had 17 panicles while T3 and T4 both obtained 18 panicles (Table 4). The total number of spikelets including the number of filled grains was not affected by pesticide and fertilizer management. The average number of spikelets per panicle ranged from 85-90 while the number of filled grains per panicle ranged from 48-53.

The seemingly contrasting results (grain and straw yields versus yield components) could be due to the effect of uneven degree of ripeness of the grains at harvest between treatments. Generally, plants receiving less $\mathrm{N}$ (e.g. the control, T1 and organic only, T2 treatments) mature earlier than those that receive high rates of $\mathrm{N}$ (T3 and T4). This was evident with the significantly higher number of immature spikelets from T3 and T4 as reflected by the significantly higher unfilled spikelets of 42 and 41 for T3 
and $\mathrm{T} 4$ as compared to 35 and 37 for T1 and T2 (Table 5). All the plots were harvested at the same time because of the impending typhoon passing through the area. Likewise, the statistical analysis of the grain yield showed high percent coefficient of variance of $17 \%$, indicating large variability between plots.

Table 2. Effect of pesticide application and fertilizer management on grain and straw yields of NSIC Rc146, NSIC Rc160, and Burdagol

\begin{tabular}{|c|c|c|c|c|c|c|}
\hline \multirow{2}{*}{ TREATMENTS } & \multicolumn{3}{|c|}{ GRAIN YIELD ( $\left.\mathrm{t} \mathrm{ha}^{-1}\right)$} & \multicolumn{3}{|c|}{ STRAW YIELD (t ha-1) } \\
\hline & M1 & M2 & Mean & M1 & M2 & Mean \\
\hline & \multicolumn{6}{|c|}{ NSIC Rc146 (2009 DS) } \\
\hline $\mathrm{T} 1$ & 3.28 & 3.33 & $3.30 \mathrm{a}$ & 8.38 & 6.45 & $7.41 \mathrm{a}$ \\
\hline $\mathrm{T} 2$ & 3.10 & 2.98 & $3.04 \mathrm{ab}$ & 8.75 & 7.2 & $7.98 \mathrm{a}$ \\
\hline T3 & 2.20 & 2.60 & $2.40 \mathrm{c}$ & 7.55 & 8.8 & $8.18 \mathrm{a}$ \\
\hline $\mathrm{T} 4$ & 2.50 & 2.93 & $2.71 \mathrm{bc}$ & 6.23 & 7.45 & $6.84 \mathrm{a}$ \\
\hline \multirow[t]{2}{*}{ Mean } & $2.77 \mathrm{~b}$ & $2.96 \mathrm{a}$ & & $7.73 \mathrm{a}$ & $7.48 \mathrm{a}$ & \\
\hline & \multicolumn{6}{|c|}{ NSIC Rc160 (2009 WS) } \\
\hline $\mathrm{T} 1$ & 3.02 & 3.05 & $3.04 \mathrm{~b}$ & 3.58 & 3.35 & $3.46 \mathrm{~b}$ \\
\hline $\mathrm{T} 2$ & 3.18 & 2.92 & $3.05 \mathrm{~b}$ & 3.48 & 4.35 & $3.91 \mathrm{ab}$ \\
\hline T3 & 3.42 & 3.28 & $3.35 \mathrm{a}$ & 4.15 & 4.38 & $4.26 \mathrm{a}$ \\
\hline $\mathrm{T} 4$ & 3.38 & 3.28 & $3.33 \mathrm{a}$ & 4.32 & 3.68 & $4.00 \mathrm{a}$ \\
\hline \multirow[t]{2}{*}{ Mean } & $3.25 \mathrm{a}$ & $3.13 \mathrm{a}$ & & $3.88 \mathrm{a}$ & $3.94 \mathrm{a}$ & \\
\hline & \multicolumn{6}{|c|}{ Burdagol (2010 DS) } \\
\hline $\mathrm{T} 1$ & 3.35 & 3.52 & $3.44 \mathrm{~b}$ & 3.00 & 3.18 & $3.09 \mathrm{c}$ \\
\hline $\mathrm{T} 2$ & 3.40 & 3.40 & $3.40 \mathrm{~b}$ & 3.22 & 3.08 & $3.15 \mathrm{c}$ \\
\hline $\mathrm{T} 3$ & 4.05 & 4.18 & $4.11 \mathrm{a}$ & 4.92 & 5.72 & $5.32 \mathrm{a}$ \\
\hline $\mathrm{T} 4$ & 4.05 & 4.38 & $4.21 \mathrm{a}$ & 4.45 & 4.28 & $4.36 \mathrm{~b}$ \\
\hline Mean & $3.71 \mathrm{a}$ & $3.87 \mathrm{a}$ & & $3.90 \mathrm{a}$ & $4.06 \mathrm{a}$ & \\
\hline
\end{tabular}

For each parameter measured, means followed by the same letter are not significantly different at $5 \%$ level of significance.

M1: With Pesticides

M2: Without Pesticides

T1: Control

T2: Organic only

T3: Inorganic only

T 4: $1 / 2$ Inorganic plus $1 / 2$ Inorganic 
Management on the yield and soil fertility of irrigated lowland rice

Table 3. Effect of pesticide application and fertilizer management on plant heights of NSIC Rc146, NSIC Rc160, and Burdagol

\begin{tabular}{|c|c|c|c|}
\hline \multirow{2}{*}{ TREATMENTS } & \multicolumn{3}{|c|}{ PLANT HEIGHT (cm) } \\
\hline & M1 & M2 & Mean \\
\hline & \multicolumn{3}{|c|}{ NSIC Rc146 (2009 DS) } \\
\hline $\mathrm{T} 1$ & 108.4 & 102.6 & $105.5 \mathrm{~b}$ \\
\hline $\mathrm{T} 2$ & 108.6 & 103.0 & $105.8 \mathrm{~b}$ \\
\hline T3 & 117.2 & 110.4 & $113.9 \mathrm{a}$ \\
\hline $\mathrm{T} 4$ & 113.7 & 105.4 & $109.6 \mathrm{ab}$ \\
\hline \multirow[t]{2}{*}{ Mean } & $112.0 \mathrm{a}$ & $105.4 \mathrm{~b}$ & \\
\hline & \multicolumn{3}{|c|}{ NSIC Rc160 (2009 WS) } \\
\hline $\mathrm{T} 1$ & 83.8 & 82.7 & $83.2 \mathrm{c}$ \\
\hline $\mathrm{T} 2$ & 83.9 & 84.1 & $84.0 \mathrm{c}$ \\
\hline T3 & 93.6 & 93.4 & $93.5 \mathrm{a}$ \\
\hline $\mathrm{T} 4$ & 88.5 & 89.4 & $89.0 \mathrm{~b}$ \\
\hline \multirow[t]{2}{*}{ Mean } & $87.4 \mathrm{a}$ & $87.4 \mathrm{a}$ & \\
\hline & \multicolumn{3}{|c|}{ Burdagol (2010 DS) } \\
\hline $\mathrm{T} 1$ & 86.5 & 84.5 & $85.5 \mathrm{c}$ \\
\hline $\mathrm{T} 2$ & 87.3 & 84.7 & $86.0 \mathrm{c}$ \\
\hline T3 & 103.5 & 101.3 & $102.4 \mathrm{a}$ \\
\hline $\mathrm{T} 4$ & 97.5 & 96.2 & $96.9 \mathrm{~b}$ \\
\hline Mean & $93.7 \mathrm{a}$ & $91.7 \mathrm{a}$ & \\
\hline
\end{tabular}

For each parameter measured, means followed by the same letter are not significantly different at $5 \%$ level of significance.

M1: With Pesticides

M2: Without Pesticides

T1: Control

T2: Organic only

T3: Inorganic only

T 4: 1/2 Inorganic plus $1 / 2$ Inorganic 
Table 4. Effect of pesticide application and fertilizer management on tiller and panicle counts of NSIC Rc146, NSIC Rc160, and Burdagol

\begin{tabular}{|c|c|c|c|c|c|c|}
\hline \multirow{2}{*}{ TREATMENTS } & \multicolumn{3}{|c|}{ TILLER COUNT (n) } & \multicolumn{3}{|c|}{ PANICLE COUNT (n) } \\
\hline & M1 & M2 & Mean & M1 & M2 & Mean \\
\hline & \multicolumn{6}{|c|}{ NSIC Rc146 (2009 DS) } \\
\hline $\mathrm{T} 1$ & 19 & 19 & $19 \mathrm{~b}$ & 17 & 16 & $17 \mathrm{~b}$ \\
\hline $\mathrm{T} 2$ & 20 & 19 & $20 \mathrm{~b}$ & 17 & 17 & $17 \mathrm{~b}$ \\
\hline $\mathrm{T} 3$ & 21 & 22 & $22 \mathrm{a}$ & 18 & 19 & $18 \mathrm{a}$ \\
\hline $\mathrm{T} 4$ & 22 & 18 & $20 \mathrm{~b}$ & 20 & 15 & $18 \mathrm{ab}$ \\
\hline \multirow[t]{2}{*}{ Mean } & $21 \mathrm{a}$ & $19 \mathrm{a}$ & & $18 \mathrm{a}$ & $17 \mathrm{a}$ & \\
\hline & \multicolumn{6}{|c|}{ NSIC Rc160 (2009 WS) } \\
\hline $\mathrm{T} 1$ & 12 & 11 & $12 \mathrm{c}$ & 10 & 10 & $10 \mathrm{c}$ \\
\hline $\mathrm{T} 2$ & 12 & 12 & $12 \mathrm{c}$ & 11 & 10 & $10 \mathrm{c}$ \\
\hline $\mathrm{T} 3$ & 15 & 16 & $15 \mathrm{a}$ & 13 & 14 & $13 \mathrm{a}$ \\
\hline $\mathrm{T} 4$ & 13 & 15 & $14 \mathrm{~b}$ & 11 & 13 & $12 \mathrm{~b}$ \\
\hline \multirow[t]{2}{*}{ Mean } & $13 \mathrm{a}$ & $13 \mathrm{a}$ & & $11 \mathrm{a}$ & $12 \mathrm{a}$ & \\
\hline & \multicolumn{6}{|c|}{ Burdagol (2010 DS) } \\
\hline $\mathrm{T} 1$ & 12 & 11 & $12 \mathrm{~b}$ & 11 & 10 & $10 \mathrm{~b}$ \\
\hline $\mathrm{T} 2$ & 12 & 12 & $12 \mathrm{~b}$ & 11 & 11 & $11 \mathrm{~b}$ \\
\hline T3 & 17 & 15 & $16 \mathrm{a}$ & 15 & 14 & $14 \mathrm{a}$ \\
\hline $\mathrm{T} 4$ & 16 & 15 & $15 \mathrm{a}$ & 14 & 14 & $14 \mathrm{a}$ \\
\hline Mean & $14 \mathrm{a}$ & $14 \mathrm{a}$ & & $13 \mathrm{a}$ & $12 \mathrm{a}$ & \\
\hline
\end{tabular}

For each parameter measured, means followed by the same letter are not significantly different at $5 \%$ level of significance.

M1: With Pesticides

M2: Without Pesticides

T1: Control

T2: Organic only

T3: Inorganic only

T4: $1 / 2$ Inorganic plus $1 / 2$ Inorganic 
Management on the yield and soil fertility of irrigated lowland rice

Table 5. Effect of pesticide application and fertilizer management on spikelet count, number of filled and unfilled grains of NSIC Rc146 (2009 DS)

\begin{tabular}{cccc|ccc|ccc}
\hline & \multicolumn{3}{c}{$\begin{array}{c}\text { SPIKELET COUNT } \\
\text { TREATMENTS }\end{array}$} & \multicolumn{3}{c}{$\begin{array}{c}\text { NUMBER OF FILLED } \\
\text { GRAINS (n) }\end{array}$} & \multicolumn{3}{c}{$\begin{array}{c}\text { NUBER OF FILLED } \\
\text { GRAINS (n) }\end{array}$} \\
\cline { 2 - 10 } & M1 & M2 & Mean & M1 & M2 & Mean & M1 & M2 & Mean \\
\hline T1 & 85 & 86 & $85 \mathrm{a}$ & 46 & 54 & $50 \mathrm{a}$ & 38 & 32 & $35 \mathrm{~b}$ \\
T2 & 92 & 88 & $90 \mathrm{a}$ & 52 & 55 & $53 \mathrm{a}$ & 41 & 34 & $37 \mathrm{ab}$ \\
T3 & 89 & 92 & $90 \mathrm{a}$ & 46 & 51 & $48 \mathrm{a}$ & 43 & 41 & $42 \mathrm{a}$ \\
T4 & 86 & 94 & $90 \mathrm{a}$ & 44 & 56 & $50 \mathrm{a}$ & 42 & 39 & $41 \mathrm{a}$ \\
Mean & $88 \mathrm{a}$ & $90 \mathrm{a}$ & & $47 \mathrm{a}$ & $54 \mathrm{a}$ & & $41 \mathrm{a}$ & $36 \mathrm{a}$ & \\
\hline
\end{tabular}

For each parameter measured, means followed by the same letter are not significantly different at $5 \%$ level of significance.

M1: With Pesticides

M2: Without Pesticides

T1: Control

T2: Organic only

T3: Inorganic only

T4: $1 / 2$ Inorganic plus $1 / 2$ Inorganic

NSIC Rc160 (2009 WS). Generally, grain and straw yields as well as yield components obtained from NSIC Rc160 were not affected by pesticide application (Table 5). Significant differences were only observed in the fertilizer management. Highest grain yield was obtained from T3 treatment with $3.35 \mathrm{tha}^{-1}$ but was not significantly different from $\mathrm{T} 4 \mathrm{which}$ yielded $3.33 \mathrm{tha}^{-1}$. Treatment 2 had $3.05 \mathrm{tha}^{-1}$ comparable with T1 at $3.04 \mathrm{t}$ $\mathrm{ha}^{-1}$. Straw yield had similar trend as grain yield. Treatments 3 and 4 had significantly higher straw yield with 4.26 and $4.00 \mathrm{t} \mathrm{ha}^{-1}$ compared to T1 and T2 with 3.46 and $3.91 \mathrm{t} \mathrm{ha}^{-1}$, respectively (Table 2). The trend in grain yield of the interaction of pesticide and fertilizer management showed generally higher grain yields of plots with pesticide application regardless of fertilizer management. This result was inconsistent with the observations in the previous crop.

For plant height, T3 produced significantly the tallest plants at $93.5 \mathrm{~cm}$ followed by T4 at $89 \mathrm{~cm}$. Treatment 2 had $84 \mathrm{~cm}$ and T1 had $83.2 \mathrm{~cm}$ plant heights which were the lowest and comparable to each other (Table 3). The same trend was observed in tiller and panicle counts. Tiller counts of T1 and $\mathrm{T} 2$ both obtaining 12 tillers were comparable and significantly lower compared to T3 and T4. Treatment 3 had the most number of tillers at 15 followed by T4 at 14 . Consequently, T3 significantly produced the most number of panicles at 13 followed by T4 at 12 . Again, T1 and T2 which both 
had 10 panicles were the lowest (Table 4). Based on the results, it can be inferred that the application of inorganic fertilizer alone or in combination with organic fertilizer at one-half rates were effective in increasing the yield of NSIC Rc160. Apparently, organic fertilizer application using compost from farm residues were not effective in improving plant growth and increasing the yield of NSIC Rc160 since in most of the agronomic parameters measured, its response was comparable with the control treatment. This may be attributed to its very low nutrient content. The study conducted by Castillo et al. (2011) evidently showed that one season application of chicken manure did not increase the yield of NSIC Rc212. Furthermore inorganic fertilizers with or without additional chicken manure are comparable in terms of grain and straw yields as well as yield components and plant nutrient uptake. Javier et al. (2002) concluded that the use of sunflower and commercial organic fertilizer gave stable yields in the first 2 years but decreased in the $3^{\text {rd }}$ year of usage.

The relatively low yields in both seasons (2009 DS and 2009 WS) could be attributed to adverse climatic conditions during the reproductive stages of the two crops.

Burdagol (2010 WS). Pesticide management did not affect the grain and straw yields and yield components of Burdagol. When treated with different fertilizer management, T4 had the highest grain yield at $4.21 \mathrm{tha}^{-1}$. Nevertheless, it was not significantly different with T3 which yielded $4.11 \mathrm{t}$ $\mathrm{ha}^{-1}$. Both T2 and T1 significantly produced the lowest yield at 3.40 and 3.44 $\mathrm{t} \mathrm{ha}^{-1}$, respectively. For straw yield, T3 obtained significantly the highest at $5.32 \mathrm{t} \mathrm{ha}^{-1}$ followed by T4 at $4.36 \mathrm{t} \mathrm{ha}^{-1}$. The lowest straw yields were observed in T1 and T2 which were also comparable at 3.09 and $3.15 \mathrm{t} \mathrm{ha}^{-1}$, respectively (Table 2 ).

Tallest plant height was observed in T3 at $102.4 \mathrm{~cm}$ followed by T4 at $96.9 \mathrm{~cm}$. It was followed by T2 and T1 which were comparable at $86.0 \mathrm{~cm}$ and $85.5 \mathrm{~cm}$, respectively (Table 3). Tiller counts of T3 and T4 which had 16 and 15 were comparable and were significantly higher than $\mathrm{T} 2$ and T1 both with 12 tillers. The same trend was observed in panicle count. Both T3 and $\mathrm{T} 4$ had 14 tillers which were significantly higher than $\mathrm{T} 2$ and $\mathrm{T} 1$ which had 11 and 10 tillers, respectively (Table 4). The results of this $3^{\text {rd }}$ season rice crop were consistent with the trend of results obtained from the $2^{\text {nd }}$ season crop which showed no significant contribution in yield and yield components of rice with the application of organic fertilizer alone. The long-term experiment on organic materials conducted by Javier et al. (2002) even showed that the yield of PSB Rc18 decreased at the $3^{\text {rd }}$ year of 
sole organic matter application (sunflower, rice straw, commercial organic fertilizer) except for chicken manure and inorganic fertilizer.

In terms of yield components of both Burdagol (2010 WS) and NSIC Rc160 (2009 WS), a higher response of plant height, tiller count, and panicle count was obtained from the plots treated with inorganic fertilizer only which was comparable to the plots applied with combined sources of organic and inorganic fertilizers and were significantly higher than the control and organic only treatments. Spikelet count and number of filled grains were not affected by pesticide and fertilizer management as observed in NSIC Rc146 (2009 DS).

Generally, pesticide application did not affect the grain and straw yields as well as the yield components of lowland rice which was evident in the $2^{\text {nd }}$ and $3^{\text {rd }}$ cropping seasons. The trend of results with the interaction of pesticide application and fertilizer management as observed in the 3 cropping seasons were not conclusive.

Fertilizer treatment results imply that the use of compost alone as organic fertilizer was not effective in increasing the yield or improving the other agronomic parameters of irrigated rice. This further indicates that there was no residual effect of nutrients from 3 consecutive seasons of organic fertilizer application since the yield data obtained for organic treatment was similar to the control even in the $3^{\text {rd }}$ season crop. The insignificant effect of organic fertilizer application to the agronomic parameters of rice may be due to its low $\mathrm{N}$ content even at the rate of $3 \mathrm{tha}^{-1}$ compared to the relatively higher amount of $\mathrm{N}$ supplied by the inorganic fertilizer. This was not enough to cause significant increases in rice yield and other yield components. The $\mathrm{N}$ content of the applied organic fertilizer only ranged from 7-13 $\mathrm{kg} \mathrm{N}$ per season while the $\mathrm{N}$ supplied by the inorganic fertilizer ranged from $120-125 \mathrm{~kg} N$ per season. In general, the combination of one-half organic and one-half inorganic fertilizers were comparable to the pure inorganic treatment. However, it cannot be concluded that the organic fertilizer applied contributed to the increase in yield. The increase in yield might be due to the inorganic fertilizer only when the amount of $\mathrm{N}$ supplied was already sufficient to provide for the $\mathrm{N}$ requirement of the rice crop. This can be further verified by including an additional treatment to the experiment which is one-half inorganic only. However, it can also be inferred that the combination of organic and inorganic fertilizer had synergistic effect improving the efficiency of both fertilizers, thus, producing yield results comparable to pure inorganic treatment. Javier et al. (2002) cited that organic fertilizer may just play a 
supplementary role but not as a sole nutrient source as far as high rice yield production is concerned. They added further that balancing the nutrient by a mixture of inorganic and organic soil amendments is more efficient than the sole use of organic fertilizer materials. Mamaril et al. (1988) noted that the combination of inorganic and organic fertilizer could be one of the measures in minimizing yield decline over time. This is because organic materials contain not only $\mathrm{N}, \mathrm{P}$, and $\mathrm{K}$ but also the other essential nutrients which are not usually present in chemical fertilizers among the prevailing high analysis fertilizers in the market. He further added that the combined application of organic and chemical fertilizers may improve the fertilizer use efficiency of the latter materials.

\section{Determination of Soil Fertility}

Table 6 shows the changes in soil nutrient status of the different fertilizer treatments based on MOET test. Prior to the experiment, the soil was found to be deficient in only nitrogen (N) and sulfur (S). Thus, the fertilizers applied in the pure inorganic treatment (T3) consisted only of $\mathrm{N}$ and $S$ at the rate of $120 \mathrm{~kg}$ and $24 \mathrm{~kg}$, respectively (See Table 1 ). On the other hand, plots treated with organic only (T2) and combination of $1 / 2$ organic plus $1 / 2$ inorganic fertilizers (T4) also contributed phosphorus (P) and potassium (K) aside from $\mathrm{N}$ and $\mathrm{S}$ because of the composition of compost used. Treatment 2 plots received 13-2-17-6 kg ha ${ }^{-1}$ NPKS while T4 had 671-9-20 kg ha ${ }^{-1}$ NPKS. The control plot (T1) was not applied with fertilizers.

Table 6. Nutrient deficiencies of the soil for each cropping season based on MOET test as affected by different fertilizer treatments

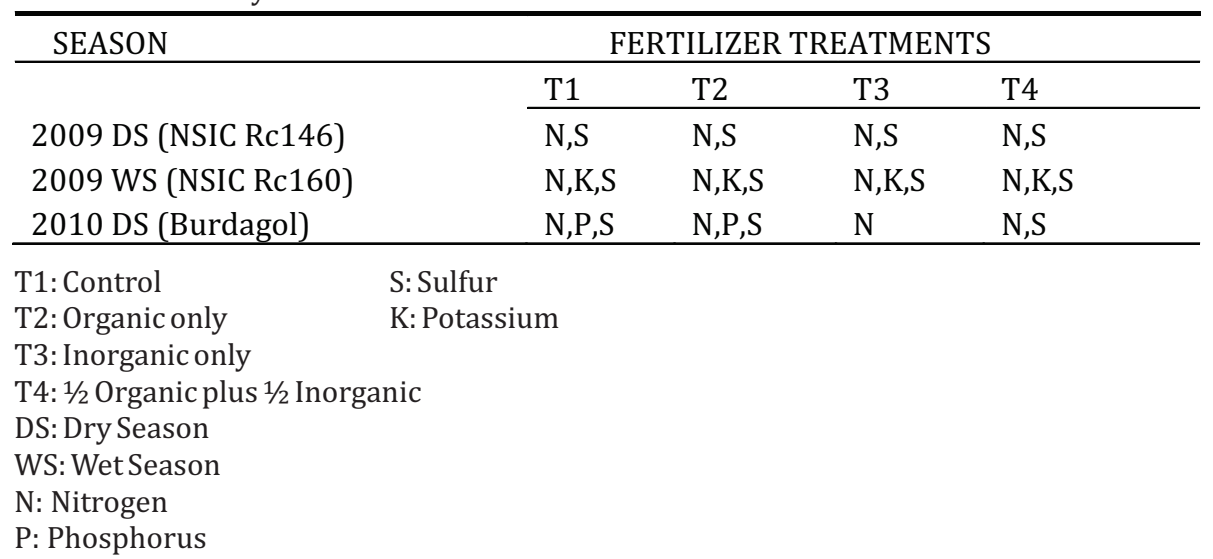


After harvest of the first crop, NSIC Rc146, the soil was again subjected to MOET analysis to determine the effect of the fertilizer management to the nutrient status of the soil specifically $\mathrm{N}$, phosphorus $(\mathrm{P})$, potassium $(\mathrm{K})$, and S. It was observed that nitrogen and sulfur were still deficient in all of the four fertilizer management treatments. Besides $\mathrm{N}$ and $\mathrm{S}$, the soil had also been deficient of $\mathrm{K}$ in all of the fertilizer treatments. This might be due to the complete removal of straw after harvest. The relatively high amount of $\mathrm{K}$ absorbed by the straw was not returned back to the soil, hence, induced the deficiency of this nutrient. Though some amount of $\mathrm{K}$ had been incorporated in $\mathrm{T} 2$ and $\mathrm{T} 4$ plots due to the addition of organic fertilizer, it was not enough to supplement the removed $\mathrm{K}$ in the soil. This may be the reason why the organic fertilizer treatments exhibited K deficiency.

Due to the limitation of nutrients observed after the first season rice crop, the inorganic fertilizer treatment (T3) of the subsequent rice crop (NSIC Rc160) was supplied with the limiting nutrients. T3 plots were applied with inorganic fertilizer containing $\mathrm{N}, \mathrm{K}$, and $\mathrm{S}$ at the rate of 120-0$30-24 \mathrm{~kg} \mathrm{ha}^{-1}$. Treatment 2 was still supplied with compost at the rate of $3 \mathrm{t}$ $\mathrm{ha}^{-1}$ with NPKS content of 10-7-7-6 $\mathrm{kg} \mathrm{ha}^{-1}$, respectively. Treatment 4 had a total fertilizer recommendation of 65-4-19-15 kg NPKS which is equivalent to the combination of one-half rates of organic and inorganic fertilizers used. After harvest, the left-over straws of NSIC Rc160 were returned back to their respective plots.

The result of MOET test conducted after the $2^{\text {nd }}$ season rice crop indicated that $\mathrm{T} 1$ and $\mathrm{T} 2$ did not show $\mathrm{K}$ deficiency; however, P deficiency manifested in addition to $\mathrm{N}$ and $\mathrm{S}$ deficiencies. Apparently, the P supplied by the organic fertilizer was not enough to meet the $\mathrm{P}$ demand of the crop. The $\mathrm{P}$ content of the T1 and T2 plots might have been precipitated by Ca or Fe resulting to unavailability of this nutrient for plant uptake. According to Mamaril et al. (2009), some organic fertilizers contain high amounts of some heavy metals. Heavy metals such as Fe cause nutrient imbalance in the soil inducing $\mathrm{P}$ deficiency. Treatment 3 , though not supplied with $\mathrm{P}$ fertilizer, did not exhibit $\mathrm{P}$ deficiency. Moreover, it corrected $\mathrm{K}$ and $\mathrm{S}$ deficiencies leaving $\mathrm{N}$ deficiency only. Treatment 4 corrected the $\mathrm{K}$ deficiency but still exhibited $\mathrm{N}$ and $\mathrm{S}$ deficiencies. The amount of $\mathrm{S}$ supplied at $15 \mathrm{~kg} \mathrm{ha}^{-1}$ in T4 plot may not be enough to amend the $\mathrm{S}$ deficiency of the soil whereas it was corrected by the inorganic fertilizer at T3 plots which supplied $24 \mathrm{~kg} \mathrm{ha}^{-1} \mathrm{~S}$. Similarly, the $6 \mathrm{~kg} \mathrm{ha}^{-1} \mathrm{~S}$ supplied by the organic fertilizer in T2 was not enough to correct the sulfur limitation of the soil. Nitrogen was found to be deficient for 3 consecutive seasons even with the 
application of organic or inorganic fertilizer sources. Nitrogen is an essential macronutrient which is required by plants in many metabolic and physiological processes to grow normally. It is almost always deficient in soils because aside from being absorbed by plants in large quantities, it is prone to losses in the soil when processes such as volatilization, denitrification, and leaching transform nitrogen into unavailable forms for plant uptake. The correction of K deficiency might be due to the recycling of rice straws from the second crop. Long term experiments at IRRI conducted by Capati (1983) have shown that incorporation of straw into the soil is beneficial because it builds up soil fertility.

It can be noted that application of limiting nutrients using inorganic fertilizers helps to correct most of soil deficiencies compared to the use of organic fertilizer alone. The nutrient content of organic materials such as compost are very low and may not be sufficient to provide the amount of nutrients required by the rice crop even after 3 cropping seasons. Incorporation of rice straw, however, is an effective strategy to correct $\mathrm{K}$ deficiency of the soil. Javier et al. (2002) proved that highest soil K was noticeably observed from the rice straw-applied plots throughout the growth stages of the rice plant because there has been an accumulation of soil $\mathrm{K}$ by continuous application of straw. The need to integrate inorganic with organic materials was further recommended to increase and sustain rice growth and grain yield.

\section{CONCLUSION}

Generally, pesticide application did not affect the grain and straw yields, and yield components of NSIC Rc146, NSIC Rc160, and Burdagol as expected. Pest population appears minimal to cause damage that will affect yield. According to Pingali (1995), in Asian rice systems, pesticide use is small in terms of dosages and number of applications, and the chemicals used degrade more rapidly in tropical flooded conditions than in the temperate upland conditions. Magalona (1989), emphasized that the rapid degradation of pesticides in general under flooded conditions both in the soil and water phases are brought about by action of anaerobic microorganisms as well as hydrolysis due to fluctuating $\mathrm{pH}$, more so with the carbamates and organophosphates.

Contrary to the higher grain yield obtained from control and organic plots compared to inorganic plots during the first cropping season planted with NSIC Rc146, it was evident from the two succeeding seasons with 
NSIC Rc160 and Burdagol rice crops that the plots treated with full rate of inorganic fertilizer and the combination of $1 / 2$ rate of organic plus $1 / 2$ rate of inorganic fertilizer had significantly higher grain yield compared to the similar yields of control and organic fertilizer plots.

In terms of yield components, a higher response of plant height, tiller count, and panicle count was obtained from the plots treated with inorganic fertilizer with or without additional organic fertilizer compared to control and organic fertilizer applied alone.

It can be noted that application of limiting nutrients through inorganic fertilizers helps to correct soil deficiencies such as S compared to the use of organic fertilizer alone. Incorporation of rice straw is an effective strategy to correct $\mathrm{K}$ deficiency of the soil because it returns the significant amount of K contained in the straw.

Organic fertilizers such as compost are slow-releasing and lownutrient containing materials, thus, application of this material alone will not suffice to produce high yields expected from a particular crop especially rice.

Long-term application of both organic materials, such as rice straw and other farm wastes, and inorganic fertilizers may help increase rice production and sustain the productivity and fertility of the soil.

Tissue and grain analysis can be done to determine the effect of various pesticide and fertilizer management on plant nutrient uptake. Long-term experiment is necessary to observe significant build-up of nutrients in the soil using organic and inorganic management.

\section{ACKNOWLEDGMENT}

The authors would like to thank PhilRice for funding this research project. This research was a collaborative project of the Agronomy and Soil Science Division, PhilRice Los Baños, Rice Chemistry and Quality Laboratory of PhilRice Los Baños, Rice Chemistry and Food Science Division, PhilRice Muñoz, and Department of Food Science, Louisiana State University, Baton Rouge, LA 70803, USA. This paper only presented the agronomic parameters observed because the results on grain quality has already been published in the Philippine Agricultural Scientist Vol. 94, June 2011 with the title "Content of tocols, $\gamma$-oryzanol and total phenolics and grain quality of brown rice and milled rice applied with pesticides and organic and inorganic nitrogen fertilizer". 


\section{REFERENCES}

AKTAR M.W., D. SENGUPTA, A. CHOWDHURY. 2009. Impact of pesticides use in agriculture: their benefits and hazards. Interdiscip Toxicol. 2009 March; 2(1): 1-12. Published online 2009 March. doi: 10.2478/v10102-009-0001-7.

CAPATI A.M.B. 1983. Improving the fertility of wetland rice soils by straw and water management. MS thesis, University of the Philippines Los Baños, Laguna, Philippines.

CASTILLO M.B., E.S. PATERNO, P.B. SANCHEZ, R.B. BADAYOS, P.C. STA. CRUZ. 2011. Enhancing Lowland Rice (Oryza sativa L.) Production Through Management of Rice Straw During the Fallow Period. MS Thesis, University of the Philippines Los Baños.

COSICO W.C. 2010. Overview of organic fertilizer use in rice in the Philippines. In: Revisiting the Organic Fertilizer Issue in Rice, Annual Rice Forum 2009. Asia Rice Foundation, College, Laguna 4031, Philippines. Pp. 1-15.

DESCALSOTA J.P., C.P. MAMARIL, G.O. SAN VALENTIN, A.L. AYO, T.M. CORTON and S.R. OBIEN. 2002. Minus-One Element Technique of diagnosing nutrient limitations and balancing fertilizer application in lowland rice soils. PhilRice Technical Bulletin. 6(2):1-6. Muñoz, Nueva Ecija: Philippine Rice Research Institute.

JAVIER E.F., J.M. MARQUEZ, F.S. GROSPE, H.F. MAMUCOD, R.E. TABIEN. 2002. Three-year effect of organic fertilizer use on paddy rice. Philippine Journal of Crop Science 2002, 27(2):11-15, Copyright 2004, Crop Science Society of the Philippines.

LALES J.S. 2008. Ten-year productivity of irrigated lowland rice under different levels of organic and inorganic fertilizers. Philippine Journal of Crop Science 2008, 33(2):59-74, Copyright 2008, Crop Science Society of the Philippines.

MAGALLONA E.D. 1989. Effects of Insecticides in Rice Ecosystems in Southeast Asia. In: Ecotoxicology and Climate. Published by John Wiley \& Sons Ltd. 
MAMARIL C.P., M.B. CASTILLO, L.S. SEBASTIAN. 2009. Facts and myths about organic fertilizers. Maligaya, Science City of Muñoz, Nueva Ecija: Philippine Rice Research Institute. 118 p.

MAMARIL C.P., M.S. CABRERA, D.I. ESTRELLA, E.M. DE GUZMAN. 1988. Combined use of inorganic and organic nitrogen fertilizers in lowland rice. Paper presented at the International Symposium on Balanced Fertilization on November 7-12,1988 at Beijing, China.

NWILENE F.E., A. TOGOLA, O.E. OYETUNJI, A. ONASANYA, G. AKINWALE, E. OGAH, E ABO, M. UKWUNGWU, A. YOUDEOWEI, N.WOIN. 2011. Is Pesticide Use Sustainable in Lowland Rice Intensification in West Africa? Pesticides in the Modern World - Risks and Benefits (M. Stoytcheva, ed), ISBN: 978-953-307-458-0, InTech, Available from: http://www.intechopen.com/books/pesticides-in-the-modernworld-risks-andbenefits/is-pesticide-use-sustainable-in-lowlandrice-intensification-in-west-africa. pp 331-320.

PINGALI P.L. 1995. An overview of results from a multiciplinary study in the Philippines. In: Impact of pesticides on farmer health and the rice environment. Natural Resource and Management Policy. United States of America.

TILO, S.N and G.O. SAN VALENTIN. 1984. Crop residues/farm manures. Mimeographed report. Los Baños, Laguna: University of the Philippines Los Baños-Farming Systems and Soil Resources Institute. 